\title{
Preventing and combating hate crimes: Modern approach
}

\author{
Jelena Groma
}

The Central Criminal Police Department of the State Police of Latvia, Latvia

\begin{abstract}
A sufficient body of research, originally American and British, as well as practice has been accumulated in the last decades in the field of hate crime. Modern understanding of the issue distinguishes multinational and global character of the harm appearing due to hate crime, thus setting up topicality of this crucial problem. This paper is aimed at description of measures of effective prevention of hate crime and general considerations for an effective strategy of hate crime prevention and combating proposed by well recognized specialists in the field, mentioning prioritizing the response to hate crime within the police department, establishing multi-agency task forces, training police officers, responding to hate-crime victims' needs, increasing police presence and attention in highrisk neighbourhoods, monitoring hate groups and tracking hate incidents, reaching out to minority communities, engaging educational institutions and the mass media. Reporting on recent development of Latvian Criminal Law regulation related to hate crime author sets up some specific problematic issues and discusses solution options.
\end{abstract}

Key words: hate crime, effective prevention, public safety, conflict, victims, community.

\section{Introduction}

More than a decade ago R. Oakley [1] distinguished and addressed to Member States some general provisions preventing and combating racism and hate crime as the follows: creation of an adequate legal and public policy framework to empower the police to effectively tackle racist crime; existence of public commitment; initial recording of the crime as "racially motivated" any crime when a victim or witness consider to be racially motivated, so that any subsequent investigation can consider "racial motivation" as a possible factor, simultaneously making it available for (anonymous) statistical analysis; clear procedural and practical guidance should be issued to the police about how effectively respond to crime emphasising and prioritising victims' needs; necessity of initial and inservice police training, and individual police officers' training appointed at the regional or local level provided by specialists; establishment of partnership with NGOs and community groups.

\section{Understanding and legal definition of hate crime}

In our days OSCE ODIHR defines a hate crime is a crime that is motivated by bias towards a certain group within society [2]. For a criminal act to qualify as a hate crime, it must meet two criteria: the act must be a crime under the criminal code of the legal jurisdiction in which it is committed, and the crime must have been committed with a bias motivation. "Bias 
motivation" means that the perpetrator chose the target of the crime on the basis of protected characteristics. In turn, a "protected characteristic" is a fundamental or core characteristic that is shared by a group, such as race, religion, ethnicity, language or sexual orientation. The target of a hate crime may be a person, a group of people or property associated with a group that shares a protected characteristic. OSCE interpret hate crimes as crimes based on prejudice [3]. Individual hate crimes carry the seeds of potential conflict, as they can escalate both in terms of the number of incidents and the level of violence. Other authors [4] deciphering hate crimes also called bias crimes define these as offenses where "the offender intentionally selects the victim because of the victim's actual or perceived race, colour, religion, national origin, ethnicity, gender, disability, or sexual orientation." Strongly and effectively countering hate crimes remains a pillar of ODIHR's work on tolerance and non-discrimination issues. The Office's approach is based on strengthening the abilities of governments and civil society to recognize and address hate crimes and on the recording and reporting of hate crime data. Civil society plays a central role in promoting tolerance and supporting the victims of hate crimes. Its role as the essential partner was underlined throughout ODIHR's efforts in 2015. As part of its efforts to strengthen civil society, ODIHR also organized a number of workshops on hate crime, many of which also provided platforms for dialogue with government officials and other international organizations [5].

An international body of research, accumulated over the past two decades, suggests differences distinguishing the psychological trauma experienced by hate crime victims compared with victims of non-bias crime [6]. Modern understanding of the harm appearing due to hate crime brings an idea why hate crimes are bearing some specific features, and should be treated differently from other crimes [7]. The authors of these guidelines specify hate crimes as crimes that tend to increase, escalate and spiral. They report that perpetrators acquire feeling that they are acting on behalf of their community, and they feel morally justified in their behaviour. If that community does not effectively punish and repudiate hate crimes, perpetrators become encouraged to continue their activities, and the number of hate crimes increases. Offenders who start committing minor offences continue to commit increasingly violent acts if they are not caught and stopped. Therefore, even minor offences committed with bias motivation are dangerous.

\section{Measures of effective prevention of hate crimes}

If victims and their communities feel unsafe and unprotected by state authorities, they are likely to retaliate against members of the community that is blamed for attacking them. This can lead to further attacks, creating a spiral of violence that leads to serious social breakdown. Summarizing, the authors suggest that in countries with a history of ethnic conflict, this is a particularly prominent phenomenon. Other authors [8], studying problems related to ethnic crime state that the current geopolitical and economic reality needs modernisation of the approach to the detection, prevention and counteraction to ethnic crime. Therefore, taking into consideration the significance of the problem, they suggest reference to the migrants' ethnic criminal activity in the framework of a special legal regime. It means that all public relations connected with the detection, prevention and counteraction to ethnic crime and other legal measures should be evaluated not only from the perspective of statutory regulation, but also in the context of real practice in this area. A realistic interpretation reflects the actual state of legal practice, which makes the selection of legal regimes in different scales possible.

Many national strategies on public safety and security distinguish crime prevention as an essential part of these. The concept of prevention postulates that crime and victimization are driven by many causal or underlying factors. These are the result of a wide range of factors and circumstances that influence the lives of individuals and families as they grow up, 
and of local environments, and the situations and opportunities that facilitate victimization and offending. A considerable amount of research and evaluation has created the fundament for development of various approaches of crime prevention. Classifying crime prevention activities into primary, secondary, and tertiary B. Welsh and D. Farrington [9] determine that primary prevention involves measures focused on improving the general well-being of individuals, secondary prevention focuses on intervening with children and youth who are at risk for becoming offenders or victims, and tertiary prevention involves measures directed toward those who have already been involved with crime or victimization. In turn, according to the crime prevention guidelines [10] the major fields of crime prevention include developmental, environmental, situational, social and community-based crime prevention. Crime prevention through social development includes a range of social, educational, health and training programmes. Recently most developmental prevention efforts have targeted early risk factors for offending. It is worth noting that risk-focused prevention was imported into criminology from medicine and public health. The basic idea of risk-focused prevention is very simple: to identify the key risk factors for offending and to implement prevention methods designed to counteract them. Community crime prevention includes areas with high levels of deprivation, both in terms of infrastructure, services and wealth, or lack of community cohesion. This includes slums and informal settlements, or inner-city or suburban housing projects, often areas with a concentration of economic and social problems. Community crime prevention often involves the active participation of local residents and organizations in those communities and neighbourhoods. They may be involved in identifying local priorities as well as implementing responses. The term "community" can refer to small neighbourhoods, areas within a city, or small villages or towns, or in some cases groups of citizens with particular concerns. Situational crime prevention covers approaches that aim to reduce the opportunities for people to commit crimes, to increase the risks and costs of being caught and to minimize the benefits. Crime prevention through reintegration refers to all programmes that work with children, young people or adults already involved in the criminal justice system, including those in custody and returning to the community. These take place in the community, or in halfway houses or sheltered homes that provide safe accommodation and in-house support and advice, and include apprenticeship programmes, job-creation schemes, life-skills training, microcredit facilities and long-term support. It is encouraged that these programmes teach conflict resolution skills or use restorative justice approaches, such as victim-offender mediation or family or community group conferencing, are other examples of ways in which offenders can be assisted in returning to civil society. It is worth noting that all the aforementioned approaches have some advantages and disadvantages, and no one is inherently better than the others. Rather, any approach selected should form part of a strategic and balanced plan.

Defining measures of effective prevention of hate crime M. Shaw [11] outlines: (1) the need for good data collection when information about long-term experience and victimization needs to be collected as well as single events or incidents; (2) existence of specific legislation acts; (3) training in the criminal justice field; (4) development of social, economic, educational and cultural programmes and strategies for targeting of both, a wider population and specific groups; (5) employment as a crucial factor for reinforcing social and economic cohesion, and fighting the conditions which favour hate and bias; (6) bringing together people of different races/sexual orientation/religion/national origin to help to demystify ignorance and suspicion.

Other authors [12] reporting regarding general considerations for an effective strategy of hate crime prevention mention: prioritizing the response to hate crime within the police department, establishing multi-agency task forces, training police officers, responding to hate-crime victims' needs, increasing police presence and attention in high-risk 
neighbourhoods, monitoring hate groups and tracking hate incidents, reaching out to minority communities, and engaging educational institutions and the mass media.

Estimating the effectiveness of hate-crime units, there is some evidence that such units send a positive message to the community that hate crimes are taken seriously, and this in turn could improve police-community relations, and lead to increased hate-crime reporting from the community. Establishing task forces to coordinate across agencies composed of federal, state, other local police agencies and prosecutor offices will facilitate the sharing of information on violent hate groups and hate-crime suspects between and among departments. M. Rowe [13] defining the role of police in prevention of hate crime outlines the ways in which the occupational culture of the police service characterized by loyalty to colleagues and membership can inhibit efforts to challenge hate. He indicates the lack of a clear link between the attitudes and values of police officers and the way in which they actually behaviour while on duty, and the need to consider police culture against the broader structural and institutional position of the police service in wider society. It is worth noting that victims of hate crime not only have the direct experience of the crime, but often also encounter double or secondary victimisation through biases and the blame of people and institutions they come in contact afterwards, therefore, the fear of being treated unfairly and negatively by those who are supposed to help affects the willingness of the victims to report and seek help for recovery [14].

- It was found that some online news portals and internet versions of newspapers providing information about topical events in Latvia and in the world have not introduced clear and comprehensive terms use, or rules for publishing comments, such as stating what kind of content is prohibited, and defining the right of the web site administration to delete the material if its content violates the terms. Development and publication of such terms, which would also refer to the liability for incitement to hatred defined in the Criminal Law, would be a preventive mechanism helping internet users to be aware of own rights and responsibility.

- It was found that a number of internet portals do not have relevant online tools to report about comments, which violate the terms of use. Therefore, the only way to remove such comments is to communicate to the editors by email. However, the LCHR practice shows that in certain cases only the editors respond and remove the content. The absence of reporting tools makes reporting more difficult because it requires far more time and requires saving the hateful comments separately and sending to the site editors. Therefore, comments remain unreported and published online.

- The monitoring confirmed that the response and reaction time of the site administration to reported hate speech comments is affected by factors such as specific content of the article, number of comments and time of the day. Therefore, in some cases, portals ban function of commenting or make it available to registered users only [15].

\section{Conclusions}

Problematic issues have been already recognized arise from a fact that computed virtual environments identified or not identified as a public space are not clearly defined in the legal acts. Therefore, practitioners are not able to apply effectively the legal norms of Criminal Law, when triggering of national, ethnic and racial hatred has been suspected or recognized.

The State Police of Latvia suggests that to increase the effectiveness combating hate crimes along with prevention of hate crimes, obligations applicable to the owners and moderators of internet portals stated as necessity to turn attention to the wider range of 
comments acting as triggers of national, ethnic and racial hatred, and assessment of risk of criminal liability should seem to be written in the legal acts.

Based on the analysis done, the author suggests that only existence of carefully verified action plan for tackling hate crime supported both by government, society and law enforcement agencies, will ensure high effectiveness of results in a life-long perspective.

\section{References}

[1] R. Oakley, Policing racist crime and violence: A comparative analysis (2005)

[2] ODIHR's Efforts to Counter Hate Crime, OSCE/ODIHR, Warsaw (2016), http://www.osce.org/odihr/68668?download=true

[3] Understanding hate crimes, OSCE/ODIHR, Warsaw, p. 16 (2012), http://www . osce.org/odihr/104166?download=true

[4] J. Freilich, S. Chermak, Hate Crimes Problem-Oriented Guides for Police, N 72 (2013)

[5] OSCE/ODIHR Annual report 2015, OSCE/ODIHR, Warsaw, p. 65 (2016), http://www.osce.org/odihr/248251?download=true

[6] P. Iganski, S. Lagou, The psychology of hate crimes as domestic terrorism (Sanata Barbara, California: Praeger, 2016), 279-292

[7] Understanding hate crimes, OSCE/ODIHR, Warsaw, p. 16 (2012), http://www . osce.org/odihr/104166?download=true

[8] J. Zieliński, I. Pikuleva, Formation of Special Legal Regime of Ethnic Crime Prevention in Context of Forced Migration. Rīga Stradinš̌ University Faculty of Law Electronic Scientific Journal of Law. Rīga, RSU, 2(5), 9-14 (2016)

[9] B. Welsh, D. Farrington, The Future of Crime Prevention: Developmental and Situational Strategies (Cambridge University, 2010), pp. 2, 65 p

[10] Handbook on the Crime Prevention Guidelines, Making them work. Vienna, UNITED NATIONS (New York, 2010)

[11] M. Shaw, http://www.crime-prevention-intl.org/fileadmin/user_upload /Publications/2005-1999/2002.ENG.Preventing_Hate_Crimes_International_Strategies_and_Practice.pdf

[12] J. Freilich, S. Chermak, Hate Crimes Problem-Oriented Guides for Police, N 72 (2013)

[13] M. Rowe, Policing, race and racism (Routledge, London and New York, 2012), p. 15

[14] I. Dzelme, Psychological Effects of Hate Crime - Individual Experience and Impact on Community Riga: Latvian Center for Human Rights (2008), p. 47

[15] The LCHR concluded the first stage of online hate speech monitoring project, http://cilvektiesibas.org. Iv/en/news/the-lchr-concluded-the-firststage-of-online-hate-325/ 